Discussion Papers

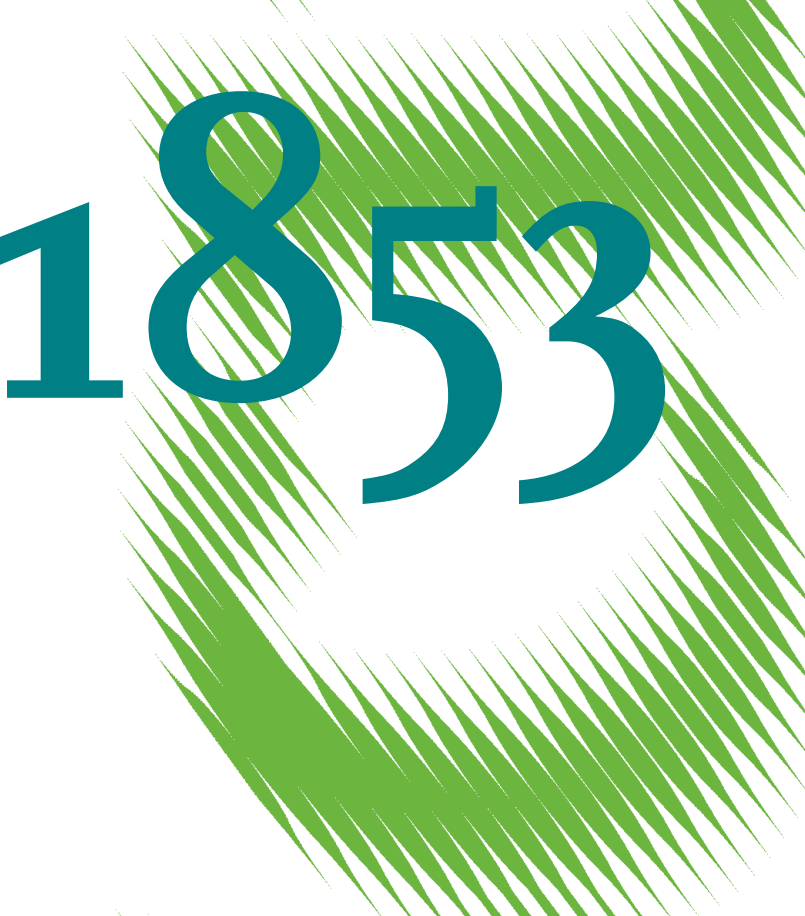

Industrial Demand Response:

How Network Tariffs and Regulation Do (Not) Impact Flexibility Provision in Electricity

Markets and Reserves 
Opinions expressed in this paper are those of the author(s) and do not necessarily reflect views of the institute.

IMPRESSUM

(C) DIW Berlin, 2020

DIW Berlin

German Institute for Economic Research

Mohrenstr. 58

10117 Berlin

Tel. +49 (30) $89789-0$

Fax +49 (30) $89789-200$

http://www.diw.de

ISSN electronic edition 1619-4535

Papers can be downloaded free of charge from the DIW Berlin website:

http://www.diw.de/discussionpapers

Discussion Papers of DIW Berlin are indexed in RePEc and SSRN:

http://ideas.repec.org/s/diw/diwwpp.html

http://www.ssrn.com/link/DIW-Berlin-German-Inst-Econ-Res.html 


\title{
Industrial Demand Response: How Network Tariffs and Regulation Do (Not) Impact Flexibility Provision in Electricity Markets and Reserves

\author{
Jörn C. Richstein* and Seyed Saeed Hosseinioun
}

\begin{abstract}
Incentives for industrial loads to provide demand response on day-ahead and reserve markets are affected both by network tariffs, as well as regulations on the provision of flexibility in different markets. This paper uses a numerical model of the chlor-alkali process with a storable intermediate good to investigate how these factors affect the provision of demand response in these markets. We also model the effect of network tariffs and regulation on endogenous investment into process excess capacities, which are needed to provide load shifting. We find that fixed network tariffs based on peak-demand (demand charges) can be detrimental to the provision of demand response, especially to new investments in process capacity. For existing excess capacities, only high network tariffs inhibit demand response by limiting the optimal peak load below its physical limit. Marketing flexibility on the day-ahead market and in the reserves are substitutes for each other. The choice where to market flexibility is affected both by fixed peak-demand network tariffs and existing excess capacities. For endogenous investments, there are synergies between primary reserve participation and day-ahead flexibility provision, with the combination leading to increased capacity investments. In contrast, so-called interruptible load reserves, regular payments to industrial loads to be able to reduce electricity consumption at any point in time, incentivize a flat demand level. Consequently, such reserve markets reduce investments into additional flexibility capacities and often crowd out active participation in other markets.
\end{abstract}

Keywords: demand response, optimization, day-ahead market, reserves, network tariffs, chemical production

JEL:C61, L65, Q40, Q48

*Corresponding author. Both authors are affiliated with German Institute for Economic Research (DIW Berlin), Climate Policy Department, Mohrenstr. 58, 10117 Berlin, Germany. 


\section{Introduction}

Demand response is expected to play a growing role in renewable dominated power systems, as traditional flexibility options, like conventional power plants, are dismantled. As intermittent renewable sources are not freely dispatchable (and at least limited in the upper output), and less load-following power plants exist, parts of the electricity demand could play the role of continuously matching supply with demand.

Industrial demand response is often seen as a first step in realizing the demand response potential. There is a significant potential to deploy industrial demand response, estimated at 2 to $3 \mathrm{GW}$ in Germany alone (Paulus \& Borggrefe, 2011). Other advantages of industrial demand response relative to other loads include the large size of individual processes, existing control infrastructure, as well as exposure to varying electricity prices via fine-grained metering, which reduce transaction costs for realizing the untapped potentials.

This paper uses a numerical model of an industrial demand response process, the Chlor-Alkali production process, to investigate several regulatory options and their impact on flexibility provision in the day-ahead and reserve markets. Specifically, active participation in the dayahead market, the primary reserve and the interruptible load reserve is co-optimised, under varying levels of fixed network tariffs. The day-ahead market is the primary wholesale electricity market, with varying hourly prices. The primary reserve is used to continuously balance supply and load in the power system. Participating units provide a symmetric band of flexibility within a short time-frame ( 30 seconds). The interruptible load reserve was introduced in 2013, and remunerates loads to be always available for (voluntary) load shedding.

We find that fixed network tariffs based on peak-demand (demand charges) can be detrimental to the provision of demand response, especially to new investments in process capacity. While the day-ahead market and the reserves are substitutes for each other in operation, the day-ahead market and primary reserve can jointly lead to increased investment in flexibility. The interruptible load reserve (AbLaV) on the other hand mutes investment signals in flexibility.

The paper is structured as follows. Section 2 discusses the existing literature on barriers to (industrial) demand response and existing numerical models of industrial demand response processes. Section 3 describes the developed numerical model and parameterization. Section 4 introduces the investigated scenarios and presents the results as well as a discussion. Section 5 concludes the paper and makes policy recommendations.

\section{Literature review}

There is a broad literature on the relevance of industrial demand response and potential barriers to its realization, as well as literature on the modelling of technical demand response processes; however, little model-based quantification of specific regulatory impact exists.

On the relevance of industrial demand response processes, for energy intensive industries around 2 to $3 \mathrm{GW}$ of load reduction potential has been found and around $0.3 \mathrm{GW}$ to $1.3 \mathrm{GW}$ of potential load increases (Gruber, 2017; Klobasa, 2007; Langrock et al., 2015; Paulus \& Borggrefe, 2011). If cross-sectional technologies are included, Gils (2014) finds total industrial potentials of $4.4 \mathrm{GW}$ of load reduction and 0.8 for load increases, which corresponds to nearly $5 \%$ of peak demand. This is similar to the industrial demand response potential in the Nordic countries of 4.7 to $7.1 \%$ of peak demand, as determined by Söder et al. (2018). 
The chlor-alkali process is modelled in the literature for demand response purposes. Otashu and Baldea (2019) give an overview of the existing literature and model the process dynamically on an electro-chemical, mass and thermal level, simulating a price-based demand-response operation of the process (with chlorine liquification) for a three-day horizon, finding a 7.3\% reduction in electricity costs. Studies on further processes exist; Summerbell et al. (2017) model cost and carbon reductions from cement plants, Bohlayer et al. (2020) participation in sequential electricity markets and production-inventory planning for a cement plant using a stochastic optimization, while Ramin et al. (2018) model a metal casting process. However, we could not identify studies of industrial demand response that model participation in the day-ahead market and several reserves, including regulatory aspects, such as grid tariffs and reserve design.

Barriers to demand response have been identified in the literature. Vallés et al. (2016) identify several regulatory barriers in distribution networks in general (where some industrial demand response is also located), among them the burden of smart metering and data management, the regulation with regard to the domain of the activities supported by distribution system operators, issues of network tariff structures including flexibility and cost-reflectiveness, inefficient market design for incorporating demand response in distribution networks, as well as the lack of consumer awareness about the implications of engagement in demand response. Eid et al. (2016) discuss further barriers, such as the necessity for large initial technology investments, lack of coordination between market actors, possibly resulting higher GHG peaks, and limited possibility of demand response to participate in reserve markets (with or without aggregation). Ambrosius et al. (2018) show that while welfare increases with the utilization of demand response, the absence of locational prices leads to suboptimal allocation of flexible industrial demand. Pérez-Arriaga et al. (2017) point out that fixed network charges ("demand charges" based on the (yearly) peak consumption of single actors) may lead to significant economic distortions, as individual peaks will not necessarily coincide with the system peak that is causing the need for the marginal investment of new transmission and distribution capacity.

\section{Material and Methods}

In the following, the chemical process on which the Chlor-alkali production process is based is briefly described and then the numerical model representation is developed.

\subsection{Chemical process}

The specific technical Chlor-alkali production process investigated here is membrane based for the production of ethylene-dichloride (EDC), which is an intermediate good for producing polyvinylchloride (PVC). The technical description, the parameterization and assumptions are based on Ausfelder et al. (2018), and verified by personal interviews with practitioners. The considered chloride production is based on electrolyzing brine (a sodium chloride/salt solution) in membrane cells, according to the following reaction:

\section{$2 \mathrm{NaCL}+2 \mathrm{H}_{2} \mathrm{O} \rightarrow \mathrm{Cl}_{2}+\mathrm{H}_{2}+2 \mathrm{NaOH}$}

In the next step, Chlorine and Ehylene are transformed to EDC in a catalytic reaction:

\section{$\mathrm{Cl}_{2}+\mathrm{H}_{2} \mathrm{C}=\mathrm{CH}_{2} \rightarrow \mathrm{ClH}_{2}-\mathrm{CH}_{2} \mathrm{CL}$}

EDC is an odorless liquid and, albeit toxic, easily storable in tanks. As the process to produce PVC after the EDC storage tank is a continuous process, which needs to run without interruption, it is a reasonable approximation, to simply model the flexible part up to the EDC storage for demand response purposes. 


\subsection{Model description}

In the following, we develop a numerical model of the demand response capabilities of a ChlorAlkali production process, incorporating not only different regulatory regimes but also with endogenous and exogenous capacity decision scenarios. The model is a linear program, with the objective to minimize costs of procuring electricity on the day-ahead market, while considering the technical constraints of the process (derived from the description by Ausfelder et. al., 2018 and interviews with practitioners), as well as potential revenues and requirements from the primary reserve, and the interruptible load reserve.

The indices, variables and parameters of the model are defined in Tables 1, 2, and 3.

Table 1 Indices

\begin{tabular}{|l|l|l|l|}
\hline Index & Description & Unit & Value \\
\hline $\mathrm{t}$ & time & Hour & {$[1-8736]$} \\
$\mathrm{w}$ & Weeks of the year & Weeks & {$[1-52]$} \\
\hline
\end{tabular}

Table 2 Variables

\begin{tabular}{|c|c|c|}
\hline Variable & Description & Unit \\
\hline$x(t, w)$ & Electricity required for electrolysis (per hour) & MW \\
\hline$r_{\mathrm{AbLaV}}(w)$ & Marketed AbLaV each week & MW \\
\hline $\mathrm{L}(\mathrm{t})$ & Storage level at the beginning of $\mathrm{t}$ & ton \\
\hline$X_{\max }(w)$ & $\begin{array}{l}\text { Peak required power for each week (this is the } \\
\text { maximum amount of production when there is no } \\
\text { Primary Reserve) }\end{array}$ & MW \\
\hline$X_{\text {maxyearly }}$ & Yearly peak required & MW \\
\hline$X_{\min }(w)$ & Lower production limit for day-ahead dispatch & MW \\
\hline$r_{\text {primary }}(w)$ & Marketed primary each week & MW \\
\hline$C_{\text {total }}$ & Total costs & Euro/year \\
\hline$C_{E V a r}$ & Variable electricity costs & Euro/year \\
\hline$C_{N V a r}$ & Variable network costs & Euro/year \\
\hline$C_{N F i x}$ & Fixed network costs & Euro/year \\
\hline$C_{\text {invst }}$ & Investment Costs in Electrolysis units & Euro/year \\
\hline$C_{\text {invel }}$ & Investment costs in storage & Euro/year \\
\hline$Y(w)$ & $\begin{array}{l}\text { binary variable for choosing Ablav or Primary reserve } \\
\text { participation for each week } \\
1, \mathrm{AbLaV} \text { is chosen } \\
0 \text {, Primary is chosen }\end{array}$ & {$[1 ; 0]$} \\
\hline$\overline{R_{\text {AFlex }}}$ & $\begin{array}{l}\text { Revenue from } \mathrm{AbLaV} \text { market (not one day ahead } \\
\text { market) }\end{array}$ & Euro/Year \\
\hline$R_{\text {Pflex }}$ & $\begin{array}{l}\text { Revenue from Primary market (not one day ahead } \\
\text { market) }\end{array}$ & Euro/Year \\
\hline$\overline{\bar{K}}$ & $\begin{array}{l}\text { Installed capacity of the process (parameter in } \\
\text { exogenous model) }\end{array}$ & MW \\
\hline $\bar{L}$ & Upper storage limit (parameter in exogenous model) & Ton \\
\hline
\end{tabular}




\begin{tabular}{|c|l|l|l|}
\hline Parameter & Description & Unit & Value \\
\hline$P_{\text {Elhourly,t }}$ & Hourly electricity price & Euro/MWh & Scenario \\
\hline$N_{\text {var }}$ & Variable network charges & Euro/MWh & Scenario \\
\hline$\varphi_{E L}$ & Electricity intensity of the processes & MWh/ton ${ }_{E D C}$ & 1.8 \\
\hline$N_{f i x}$ & $\begin{array}{l}\text { Fix network charges (for maximum } \\
\text { capacity) }\end{array}$ & Euro/MW & Scenario \\
\hline$P_{\text {AbLaV,Reserve }}$ & $\begin{array}{l}\text { Marketed immediately load price } \\
\text { (SOL) }\end{array}$ & Euro/MWh & $\begin{array}{l}\text { Scenario } \\
{[0,500]}\end{array}$ \\
\hline$P_{\text {primary,Reserve }}(w)$ & Primary reserve power price & Euro/MWh & Scenario \\
\hline$r_{\text {primary,MaxShare }}$ & $\begin{array}{l}\text { Maximum proportion of initial reserve } \\
\text { capacity }\end{array}$ & $\%$ & $17.5 \%$ \\
\hline$C_{e l}$ & $\begin{array}{l}\text { Investment costs per MW for each } \\
\text { electrolysis unit }\end{array}$ & Euro/MW & 1000000 \\
\hline$C_{s t}$ & $\begin{array}{l}\text { Investment costs per ton for increasing } \\
\text { storage capacity }\end{array}$ & Euro/ton & 350 \\
\hline$D$ & Demand for follow-up product & MW & 80 \\
\hline$K$ & $\begin{array}{l}\text { Minimum power consumption for } \\
\text { production }\end{array}$ & MW & $0.25 * D$ \\
\hline$\underline{L}$ & Lower storage limit & Ton & 1000 \\
\hline$I_{r}$ & Interest rate for investment & $\%$ & $15 \%$ \\
\hline$N_{p e r}$ & Investment period for the project & Year & 20 \\
\hline$M$ & $\begin{array}{l}\text { For dummy variables to choose Ablav } \\
\text { or Primar }\end{array}$ & MW & 200 \\
\hline$T_{E}$ & $\begin{array}{l}\text { It determines whether the primary } \\
\text { reserve is considered in fixed network } \\
\text { tariff }\end{array}$ & binary & Scenario \\
\hline
\end{tabular}

The objective function in relation (1) minimizes the total costs related to power consumption in the Chlor-Alkali process. This includes costs of electricity consumption in the process from procuring electricity on the market $\left(C_{E V a r}\right)$, as well as additional variable $\left(C_{N V a r}\right)$ and fixed network costs $\left(C_{N i x}\right)$. Additionally, investment costs for creating electrolysis units and providing storage capacity are incurred. Finally, the revenues provided by primary reserve flexibility $\left(R_{P F l e x}\right)$ and ABLAV $\left(R_{\text {AFlex }}\right)$ are deducted from total costs.

$\min C_{\text {total }}=C_{E V a r}+C_{N V a r}+C_{N F i x}+C_{\text {invel }}+C_{\text {invst }}-R_{\text {AFlex }}-R_{\text {PFlex }}$

Relation number (2) defines the variable electricity cost $\left(C_{E V a r}\right)$ as the sum of electricity costs (electricity consumed multiplied by its price) in each hour ( $t$ ) of the year. Relation number (3) defines the variable network tariff for variable power network costs $\left(C_{N V a r}\right)$, as the product of the variable network tariff and yearly electricity consumption. As usual for bigger consumers in Germany, the fixed network tariff $\left(C_{N i x}\right)$, is calculated in relation number (4) as the product of a power-based tariff $\left(N_{f i x}\right)$ and the yearly power peak of electricity consumption $\left(X_{\text {maxyearly }}\right.$ ). Relations (5) and (6) define, respectively, the formula of annualized investment costs for electrolysis units $\left(C_{\text {invel }}\right)$ and storage capacity $\left(C_{\text {invst }}\right)$ (Yates, 2016). Relations (7) and (8) define the revenues from the flexibility market. The primary reserve price is a weekly parameter, while the $\mathrm{AbLaV}$ price considers a constant parameter throughout the year. Nonetheless, there is a weekly choice both for the $\mathrm{AbLaV}$ and primary reserve provision (cf. relations (20) and (21)). 


$$
\begin{aligned}
C_{\text {EVar }} & =\sum_{t} P_{\text {Elhourly }, t} * x(t, w) \\
C_{\text {NVar }} & =\sum_{t} N_{\text {var }} * x(t, w) \\
C_{\text {NFix }} & =N_{\text {fix }} * X_{\text {maxyearly }} \\
C_{\text {invel }} & =\frac{C_{e e^{*}} \bar{K} * I_{r}}{1-\left(1+I_{r}\right)^{-N \text { per }}} \\
C_{\text {invst }} & =\frac{C_{s t} * L^{*} * I_{r}}{1-\left(1+I_{r}\right)^{-N \text { per }}} \\
R_{\text {AFlex }} & =\sum_{w=1}^{52} P_{\text {AbLaV,Researve }} * r_{\text {AbLaV }}(w) \\
R_{\text {PFlex }} & =\sum_{w=1}^{52} P_{\text {primary,Reserve }}(w) * r_{\text {primary }}(w)
\end{aligned}
$$

The changes in storage level between two consecutive hours (for $t>1$ ) are represented in relation (9). As can be seen, the storage level at time $t+1, L(t+1)$, is equal to that of time $t$, $L(t)$, plus the amount of storage change in period $t$. This change is introduced by the amount of electricity consumed divided by electricity intensity of the process $\left(\varphi_{E L}\right)$ defined in terms of MWh per ton of ECD. $x(t, w)$ is the amount of electricity consumed for production at time $\mathrm{t}$ while $D$ is the amount of electricity required to meet the constant demand for ECD due to the following the (not explicitly modelled) production process. For $t=1$, the equation (10) sets the inventory level with respect to that of the change in the last hour of the year $(t=8736)$. Relation (11), limits the EDC storage level between the maximum $(\bar{L})$ and minimum $(\underline{L})$, which is parameterized to 1000 tons of EDC as a precautionary inventory (to buffer for continuous production in case of technical failures).

$$
\begin{aligned}
& L(t+1)=L(t)+\frac{x(t, w)-D}{\varphi_{E L}}, \forall t>1 \\
& L(1)=L\left(t_{\text {Last }}\right)+\frac{x\left(t_{\text {Last }}\right)-D\left(t_{\text {Last }}\right)}{\varphi_{E L}} \\
& \underline{L} \leq L(t) \leq \bar{L}, \forall t
\end{aligned}
$$

As seen in relation (12), the hourly electricity consumption in the process shall not be more than the total installed capacity $(\bar{K})$ and not less than the minimum power consumption (in relation (13). $\underline{K}$ defined here as a quarter of the continuous flat demand D), as a stable process operation is not feasible below this level.

$x(t, w) \leq \bar{K}, \forall t$

In the following, the modelling of the reserves is detailed. For the primary reserve, at any time when participating in the reserve, symmetric regulation must be provided on demand. As the technical limits of the process cannot be violated, instead the operational limits are further constrained in order to be always able to supply the reserve (the actual dispatch of the reserve is not modelled). 

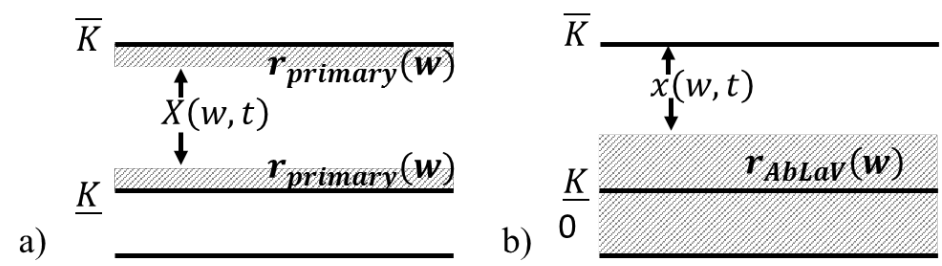

Figure 1 Constraints imposed by participation in AbLaV and primary reserve

This principle is depicted in Figure 1a. More formally, since the producer is supposed to reduce electricity consumption by an amount equal to $r_{\text {primary }}(w)$ each week for downregulation in the primary reserve market, there should be a gap between minimum power consumption for production $(\underline{K})$ and weekly minimum amount of production when there is no flexibility $\left(X_{\min }\right.$ (w)). Consequently, for each week, $X_{\min }$ should be larger than (or equal to) the sum of $r_{\text {Primär }}(w)$ and $\underline{K}$. The relation (13) encapsulates this constraint. Furthermore, for doing upregulation in primary reserve market, there should be a similar gap, this time for the difference between the total installed capacity of process $(\bar{K})$ and hourly electricity consumption each week so that the producer can, at any time, increase consumption with the amount of upregulation $\left(r_{\text {Primär }}(w)\right)$. Therefore, relation (14) is set to represent this constraint with the maximum amount of production without upregulation for primary reserve market $\left(X_{\max }(w)\right)$ plus $r_{\text {Primär }}(w)$ being less than or equal to $\bar{K}$.

$\underline{K}+r_{\text {primary }}(w) \leq X_{\min }(w), \forall w$

$X_{\max }(w)+r_{\text {primary }}(w) \leq \bar{K}, \forall w$

For AbLaV, activation works in a different manner. Here, instead of continuous balancing, the load is immediately separated from the grid (as no stable operation is required, no lower operational limit applies). Thus, in order to market the reserve, it must be connected to the grid with a minimum load, so it can be shutdown (completely) on demand (depicted in Figure 1b). Similar to the downregulation for primary reserve flexibility, for that of $\mathrm{AbLaV}$, relation number (15) shows that the amount of electricity consumption reduced each week $\left(r_{A B L A V}(w)\right)$ cannot be more than $X_{\text {min }}$ as well because in the case of AbLaV, the whole production process is ceased. We do not explicitly model the impact of the activation of the reserve on the storage, as historically activations have been very rare and, in terms of energy, small compared to the flexibility on the day-ahead market. ${ }^{1}$

$r_{A B L A V}(w) \leq X_{\min }(w), \forall w$

As one can clearly observe in relations (16) and (17), hourly electricity consumption of the process cannot be less than the corresponding weekly minimum $X_{\min }$ or more than the corresponding weekly maximum $X_{\max }$. Relation (18) determines the yearly maximum power consumption relevant for the determination of the fixed network tariff. The binary parameter $\left(T_{E}\right)$ defines two scenarios for this relation. In the case that is set equal to 1 , the yearly maximum is determined by the joint peak of energy and reserves (as is current practice for consumers with a large flat demand). Otherwise, the yearly maximum power consumption is based on a calculation without primary reserve (this is a discussed regulatory reform).

\footnotetext{
${ }^{1}$ https://www.bundesnetzagentur.de/DE/Service-Funktionen/Beschlusskammern/1_GZ/BK4GZ/2019/2019_0001bis0999/2019_0001bis0099/BK4-19-0001/BK4-19-0001_Konsultation_Ergaenzung.html
} 
$X_{\min }(w) \leq x(t, w), \forall t, \forall w$

$x(t, w) \leq X_{\max }(w), \forall t$

$X_{\max }(w)+\left(1-T_{E}\right) * r_{\text {primary }}(w) \leq X_{\text {maxyearly }}$

Another technical constraint for the studied process (19) is for the amount of flexibility for primary reserve market which, for both up and downregulation, cannot be more than $17.5 \%$ (parameter $r_{\text {primary }, \text { Maxshare }}$ ) of the total installed capacity of power consumption in the process and is a result of the required ramping speeds in the reserve.

$r_{\text {primary }}(w) \leq \bar{K} * r_{\text {primary,MaxShare }}, \forall w$

Finally, as it is assumed ${ }^{2}$ that marketing primary reserve and $\mathrm{AbLaV}$ are mutually exclusive for each week, a binary variable $(Y(w))$ is defined to decide for each week, whether primary reserve or $\mathrm{AbLaV}$ is chosen. In the case that $Y(w)$ is 1 for week $w$, only $\mathrm{AbLaV}$ is marketed. Otherwise, only primary reserve marketed for that specific week. Relations (20) and (21) demonstrates the constraint for each respective decision. The value of parameter $M$ is set in a way that makes the active constraint always feasible. For this optimization model, it is set to 200 , which is far more than the total installed capacity of the process.

$r_{\mathrm{AbLaV}}(w) \leq M * Y(w), \forall w$

$r_{\text {primary }}(w) \leq M *(1-Y(w)), \forall w$

Finally, these decision variables (relation 22) of the model should stay positive for optimization. The variables for investment and costs can have negative values.

$X(t), L(t), r_{\mathrm{AbLaV}}(w), r_{\text {Primär }}(w), X_{\text {maxyearly }}, U, \bar{L}, X_{\max }(w) \geq 0, \forall t, w$

The optimization model has a total of 17,792 variables and includes 61,639 constraints.

\footnotetext{
${ }^{2}$ This is a simplification as both can be marketed simultaneously in advance - however, non-availability in the reserve throughout the week must be declared and compensation is reduced accordingly. In principle, this could be modelled at a finer resolution.
} 


\section{Results \& Discussion}

\subsection{Scenario description}

We run a combination of different regulatory and electricity market scenarios to analyse the impact of different electricity price (and reserve price) years, network tariffs, as well as the possibility for the process to take part in the primary reserve and the $\mathrm{AbLaV}$ reserve.

Two historic years (2008 and 2015) and one future year (2030) are investigated, using data from Open Power System Data (2019) and Regelleistung.net (2019) for the historic years and from EWI (2019) for 2030, based on the DIMENSION model (Knaut et al., 2016). These years are chosen because they differ strongly in terms of absolute price levels and price spreads, thus affecting the profitability of demand response (cf. the price duration curves in Figure 2). As the primary reserve price is driven by opportunity costs for 2008 and 2015, historical prices for the same year are taken (for 2008, the reserve was procured on a monthly basis and we assumed the same monthly price for all weeks). For all years, we limit our analysis to 52 full weeks (each year starting from a Monday and ending on a Sunday), as reserves are marketed on a full week basis. Where needed, the first or last days of a year were omitted or days of the previous or following year added to have full weeks (minimizing the omitted days). This is described in more detail in the Appendix (Section A.2).

\begin{tabular}{|l|}
\hline$N_{\text {fix }}[\mathrm{EUR} / \mathrm{MW}]$ \\
\hline 0 \\
\hline 10000 \\
\hline 25000 \\
\hline 50000 \\
\hline 100000 \\
\hline
\end{tabular}

Table 4 Network tariff scenarios
Table 4 lists the investigated scenarios for fixed network tariffs (as the total consumption over the year and the variable network tariff is fixed, they do not influence decision variables. Differences in total cost can thus be computed independently from model results, and are not discussed in this paper). These fixed network tariff cover the range of typical network tariffs in Germany, including whether the network tariff is rebated according to StromNEV $\$ 19$ (2) (cf. Figure A-1 in the Appendix). Most processes on the order of magnitude of the one discussed here benefit from a reduced network tariff, thus resulting in effective prices of 10000-25000 Euro/MW for the fixed network tariff. They may lose this exception if they vary their production so much that their full load hours fall below an 8000 or 7000 hour threshold. As this regulation is not the focus of our paper, we do not explicitly model it, but will qualitatively discuss this regulation in the conclusions.

In terms of regulation, all combination of $\mathrm{AbLaV} / \mathrm{No} \mathrm{AbLaV}$ (at a price of $500 \mathrm{Euro} / \mathrm{MW}$ from prices in 2018 (Regelleistung.net, 2019) as well as no primary reserve (No PRL), primary reserve (PRL) and primary reserve with the peak network tariff exception (PRL-TE, also cf. description of Relation (18)) are investigated.

For the scenarios with exogenous capacity, setting capacities between 80 and 140MW are investigated (with $80 \mathrm{MW}$ needed to serve the internal EDC demand under a flat production), for the endogenous capacity extension this (as well the storage capacity) is set by the model.

\subsection{Flexibility Metrics}

In order to compare the flexibility provision across markets and scenarios, we define several metrics.

For the day-ahead market, two metrics are used. On the one hand, average weekly day-ahead capacity, which defines the weekly average of the spread between maximum and minimum load as: 


$$
\overline{F_{D A}}=\frac{1}{52} \sum_{w} X_{\max }(w)-X_{\min }(w)
$$

This informs about the maximum flexibility capacity provided but not the amount of energy that is flexible. Therefore, we also define the shifted DA production, as the overall storage change (only considering discharging, as otherwise shifted production would be counted twice) percentage of total demand:

$$
\gg_{D A}=\frac{\sum_{t} \max (L(t+1)-L(t), 0)}{\sum_{t} D}
$$

For the emergency load reserve $(\mathrm{AbLaV})$, we define the flexibility metric as the weekly average of marketed reserves:

$$
\overline{F_{A b L a V}}=\frac{1}{52} \sum_{w} r_{A b L a V}(w)
$$

Similarly, the primary reserve metric is defined as the average of the weekly marketed primary reserve. For proper comparison of how the capacity of the process is used as compared to the day-ahead market and $\mathrm{AbLaV}$ reserve, the primary reserve is doubled, as it is a symmetric reserve and, thus, needs double its marketed capacity (cf. Figure 1).

$$
\overline{F_{\text {primary }}}=\frac{1}{52} \sum_{w} 2 r_{\text {primary }}(w)
$$

\subsection{Exogenous Capacity decision}

The exogenous capacity decision scenarios are relevant to describe the expected flexibility behavior of processes with existing excess capacities and how regulation affects them. In the following, we first describe the flexibility provision if flexibility can only be marketed on the day-ahead market (under different network tariffs), as this serves as a base case for model.

\subsubsection{Flexibility on the day-ahead market \& the impact of tariffs}
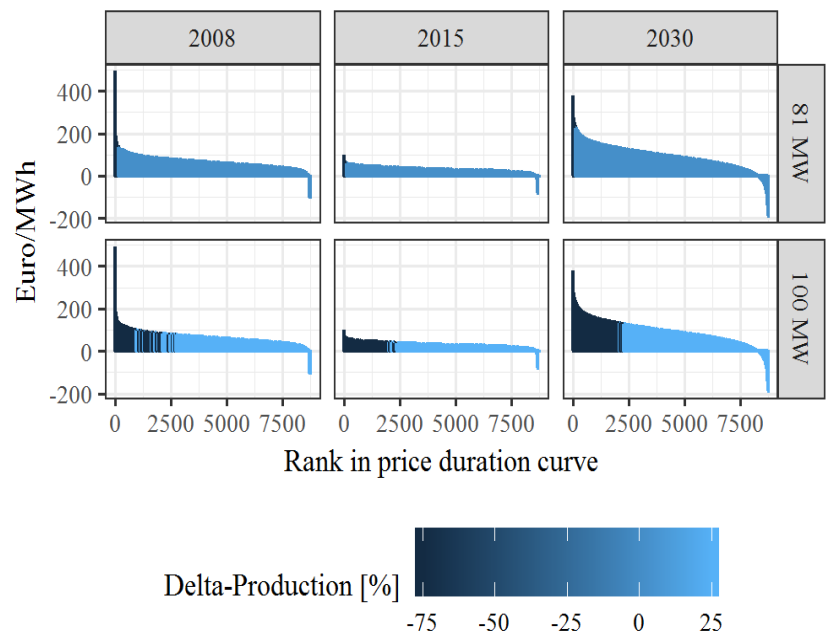

Figure 2 Production illustrated in price duration curve

Figure 2 shows the product of the process (as deviation from a flat production profile) for the price duration curves of three years in two exogenous capacity scenarios (81MW and 100MW) with no network tariffs. As is clearly shown, the expensive hours to the left of the graphs are avoided to the extent technically possible and production is shifted to the less expensive hours to the right. For a larger excess capacity, significantly more production can be shifted, as any reduction in production can quickly be compensated for by producing more in the following (or preceding) time periods. It is also notable that the lower the excess capacity, the more asymmetric in terms of delta in production (or capacity) is the provision of a high (but short) downward adjustment of demand, to a small increase in load for long periods in the remainder of the year. 
Figure 3 shows the impact of network tariffs on flexibility provision on the day-ahead market in different years, when existing excess capacities enable flexibility provision in the process. As the fixed network tariff is paid based on the maximum yearly load of the process, this could, in principle, limit flexibility provision, as an increase in maximum load, needed to compensate for demand reductions, leads to additional costs.
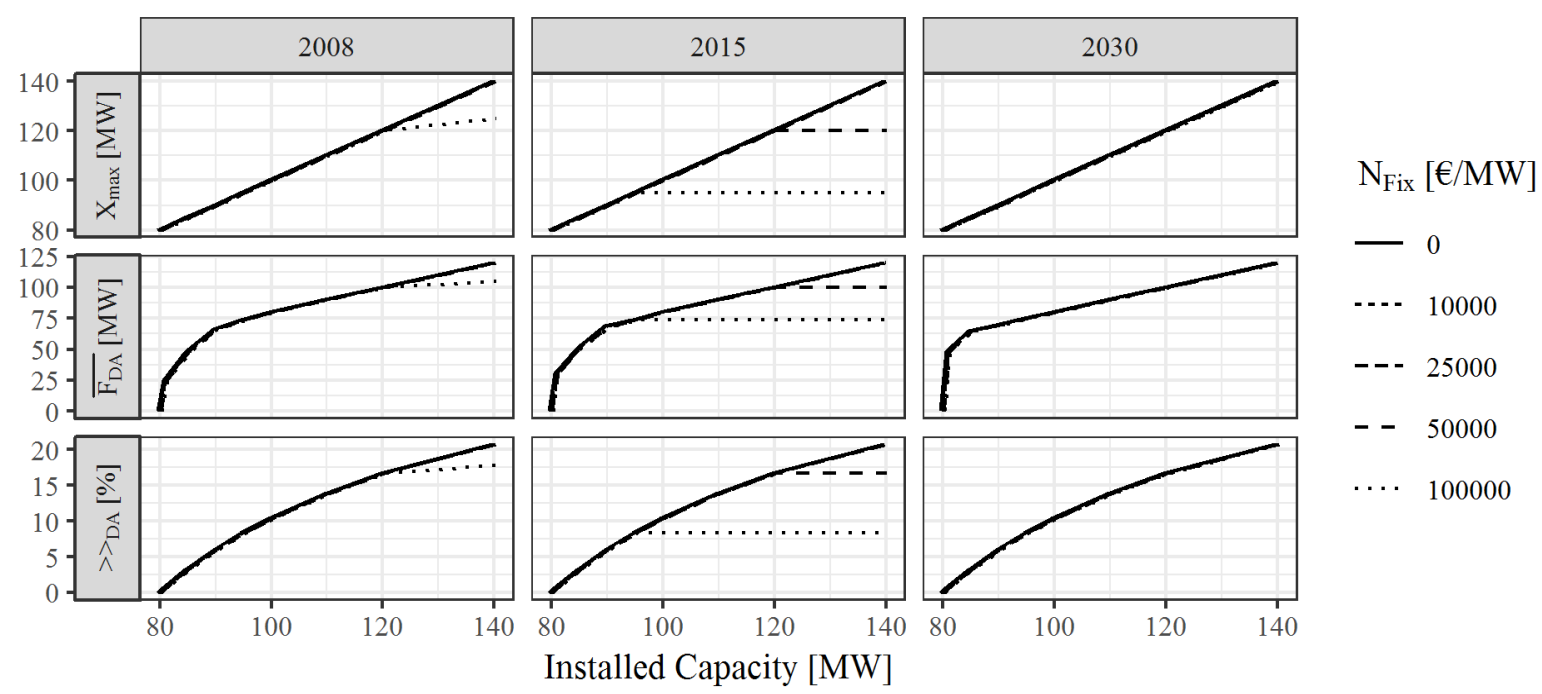

Figure 3 Impact of network tariffs on flexibility provision on day-ahead markets

When the marginal benefit of providing more flexibility is outweighed by the additional cost, only part of the available excess capacity is utilized. As shown in the first row of Figure 3, depending on the year, either network work tariffs of above 50000 Euro/MW in 2015, or 100000 Euro/MW in 2008 are necessary for this effect to occur (and there is no sufficiently high network tariff for this effect to occur in the 2030 scenario). This corresponds to typical network tariffs in Germany for users with high full load hours ( $>2500 \mathrm{~h})$, who do not profit from the exemptions for users with more than 7000h full load hours (cf. also to Figure A-1 in the appendix). Analogously, the limited maximum power peak $\left(x_{\max }\right)$, the flexibility metrics of average DA capacity $\left(\overline{F_{D A}}\right)$ and shifted production $\left(\gg_{D A}\right)$ are also limited in the case of very high network tariffs.

Figure 4 depicts the different specific cost components of the process (not counting cost for capacity that is needed to serve the baseline supply of $80 \mathrm{MW}$, variable network cost, as well as storage cost). As expected, any increase in installed excess capacity strictly reduces the wholesale electricity cost, as increased flexibility avoids the most expensive times of the year. On the other hand, this is outweighed by increased costs for excess capacity investments, as well as network tariffs. Especially for unreduced network tariffs, these reach the same order of magnitude as investments at 50000 Euro/MW or above. In terms of optimal investment decisions (discussed later in the paper), it is apparent that this strongly depends on the absolute price level in the given year, as the relative wholesale electricity costs savings are relatively similar over the years. For example, a 25\% excess capacity (100MW) leads to relative wholesale electricity savings of $86.57 \%, 87.46 \%$, and $81.16 \%$ in 2008,2015 , and 2030, respectively (see also Table A-2 in the appendix). 


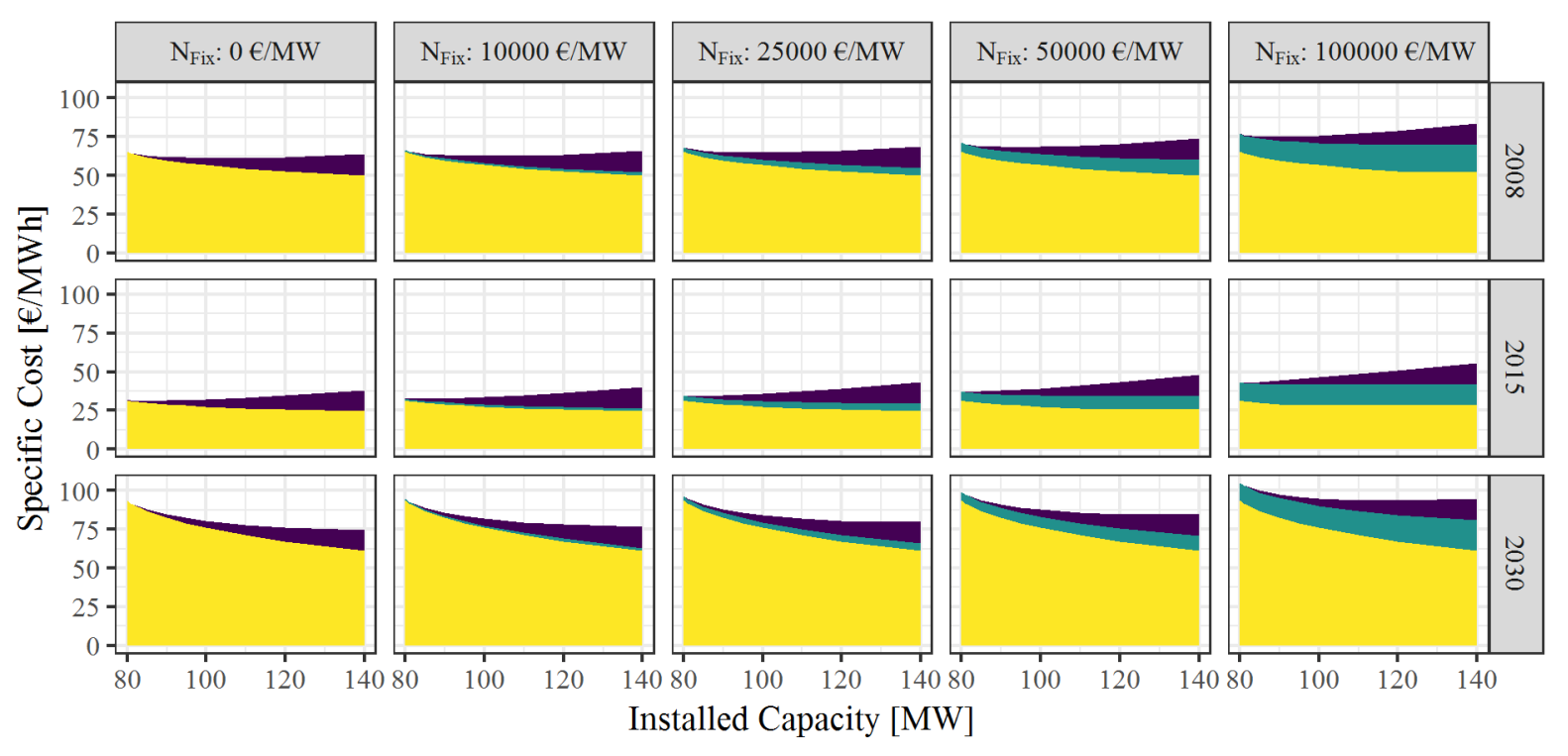

Cost Capacity Expansion $\quad$ Fixed net tariff $\quad$ Wholesale electricity

Figure 4 Specific costs of electricity consumption

\subsubsection{Day-ahead market flexibility and reserves}

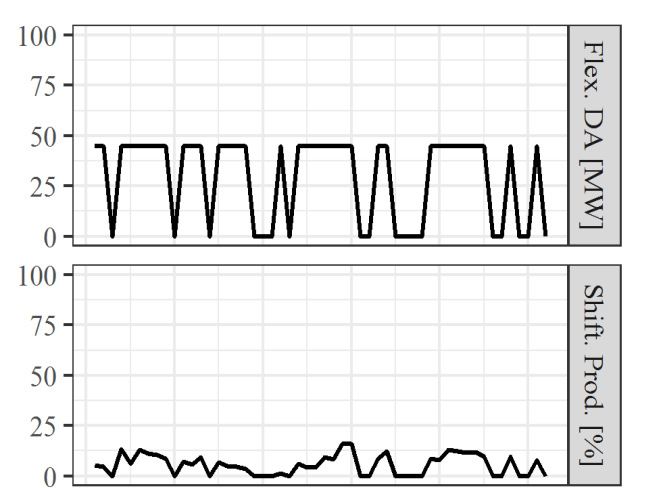

In this section, we investigate the impact the availability to market flexibility on the primary and $\mathrm{AbLaV}$ reserve has on flexibility provision under different network tariff scenarios. In the following, we make use of the aggregated yearly flexibility metrics discussed at the beginning of section 4 . These are derived from weekly flexibility indicators depicted in Figure 5. As modelled, the flexibility provision between $\mathrm{AbLaV}$ and primary reserve is an either-or decision on a weekly basis. Usually, primary reserve

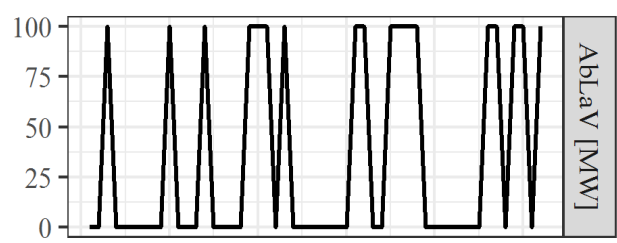
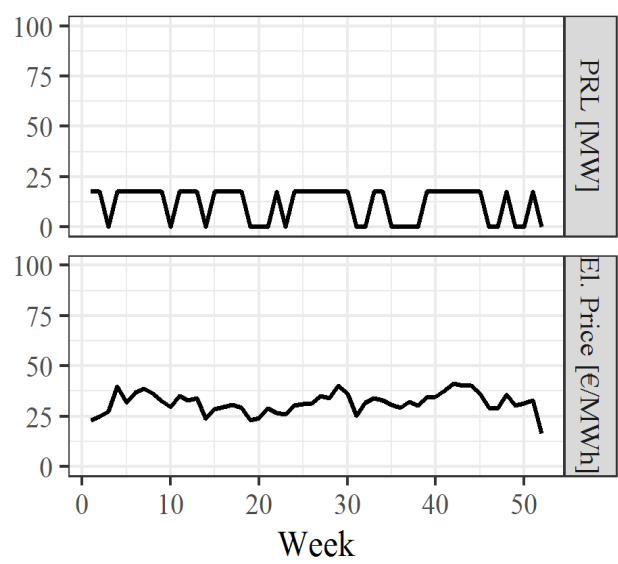

Figure 5 Weekly flexibility provision week and flexibility in 2015, for 100MW, zero network tariffs. provision is combined with DA flexibility, whereas (at this level of excess capacity), $\mathrm{AbLaV}$ is marketed exclusively by itself. Nonetheless, over the year a combination of all three flexibility provisions may occur.

Figure 6 depicts the yearly provision of flexibility over all policy and excess capacity scenarios in 2015 (the corresponding figure for 2008 is Figure A-6 in the appendix). The horizontal facets (columns of the graph) show different network tariffs, whereas the vertical facets (rows of the graph) show the different available flexibility reserve combinations. Focussing on the top two rows (only DA market and with primary reserve), the results show that flexibility provision is split between the day-ahead market and the primary reserve. Both increase with the installed excess capacity, but

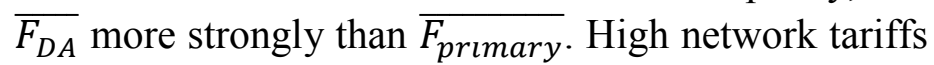
can limit the maximum flexibility capacity provided, 
due to the maximum economic limit imposed by the fixed network costs (cf. Section 4.3.1). No negative impact on the provision of primary reserve exist (in the absence of the AbLaV reserve). As a result, while the sum of marketed flexibility $\left(\overline{F_{D A}}+\overline{F_{\text {primary }}}\right)$ is equal to $\overline{F_{D A}}$ in the DAonly-scenario at low network tariffs, at higher network tariffs the combination of two reserves leads to a higher overall flexibility provision.

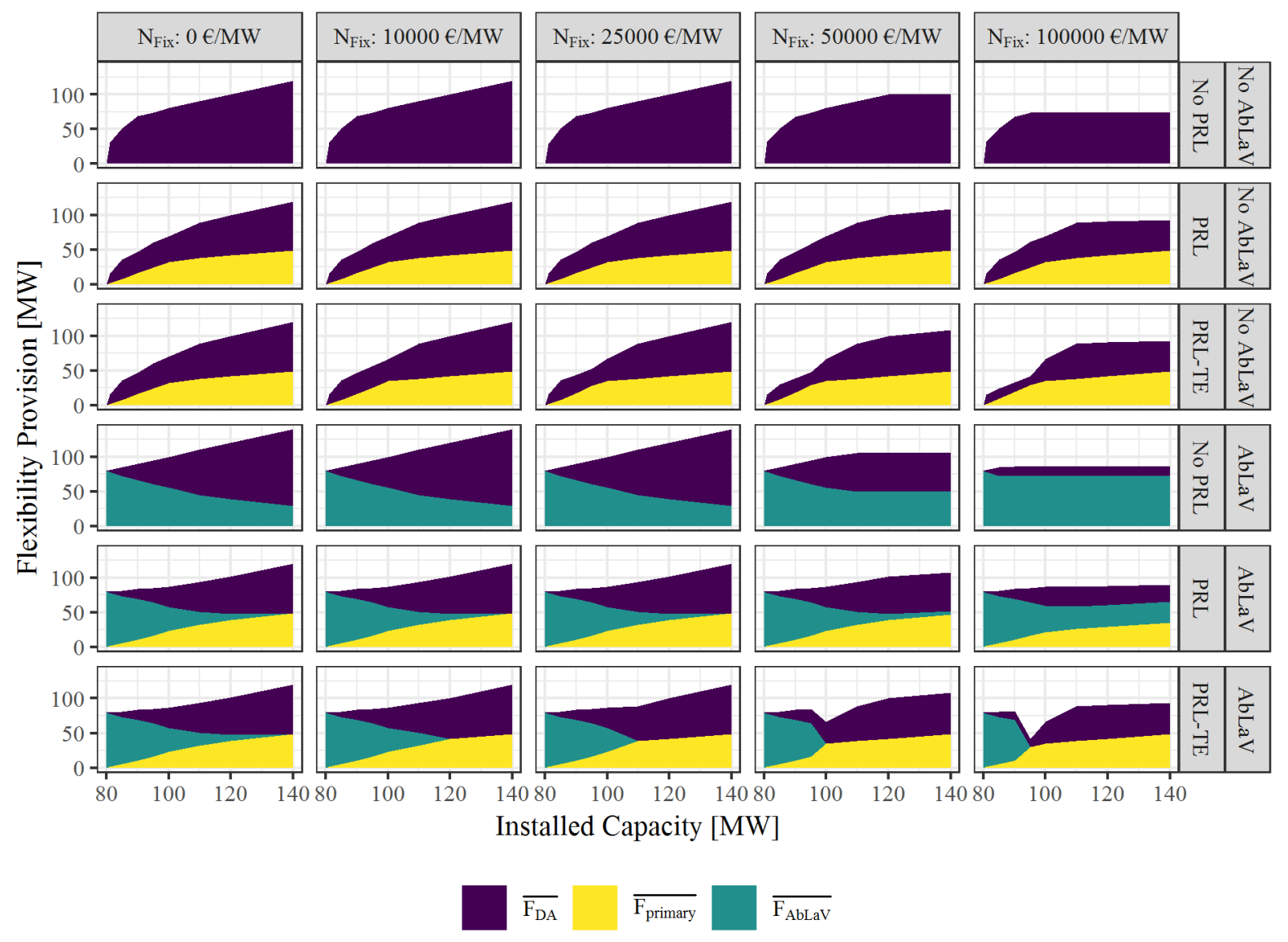

Figure 6 Flexibility provision on flexibility markets in the year 2015

When the tariff exception for the primary reserve is active (but not $\mathrm{AbLaV}$, row 3), for up to medium excess capacities, higher network tariffs lead to a provision of more primary reserve and significantly less provision of day-ahead capacities. The reason is that the limited excess capacity is all used to provide the implicitly subsidized primary reserve. Only higher excess capacities that exceed that maximum technical constraint of the primary reserve are flexibilities marketed on the DA market at larger quantities.

The interruptible loads reserve $(\mathrm{AbLaV})$ dominates in the provisioning of flexibilities at very low excess capacities (for all bottom three rows). The higher the excess capacity, the less the $\mathrm{AbLaV}$ reserve is economically advantageous. The economic reason is that in order to market the reserve, a minimum load that can always be shut off is required - so independent of the excess capacity, profits are maximised in the $\mathrm{AbLaV}$ reserve if, over an entire week, there is a flat consumption profile. As a result, the economic gain does not increase with excess capacity (as there is no spillage in the model, the process cannot be run continuously higher than the demand level). For DA and primary reserves instead, the higher is the excess capacity, the higher is the economic value of choosing one (or both) of these reserves (even though there is a decreasing marginal return to higher excess capacities). As day-ahead flexibility and PRL are 
complementing each other well, whereas participation in the $\mathrm{AbLaV}$ reserve is mostly a substitute to either, the availability of all reserves leads to very little provision of flexibility in the form of $\mathrm{AbLaV}$ at higher excess capacities (row 5).

Secondly, the interruptible loads reserve becomes more attractive at higher network tariffs (with the exception of the PRL-TE scenario). This is because high fixed network tariffs impose a cost on running the process flexibly - whereas the $\mathrm{AbLaV}$ reserve requires a flat demand. This is cancelled out in case the primary reserve is exempted from fixed network tariffs; in this case the trend is reversed and a combination of primary reserve and day-ahead capacities is preferred.

\subsection{Endogenous Capacity decisions}

So far, all discussed scenarios assume a given excess capacity; this fits if the process was over dimensioned from the beginning or if less demand than expected is realized (for example in an economic downturn).

In case investors need to make a choice regarding how much capacity to invest in, this depends on the attractiveness of the available flexibility markets. For the purpose of this investigation, we assume that demand for the follow up process needs to be served regardless of the overall electricity price level. However, it must be noted that higher electricity cost affect the overall profitability of the chemical processes. Thus, while higher absolute electricity prices (and the same relative price spread) lead to higher investments in excess capacity, these investments may not materialize if investors fear for the overall profitability of the process (for example, competitiveness as compared to other locations).

The areas in Figure 7 depict the marketed flexibility (in the same metrics as before), under different policy and network tariff scenarios (rows) and the two different years (columns). The black line represents the overall installed capacity, the dotted line the maximum power demand relevant for determination of the fixed network tariff (the two lines only diverge in the case of the PRL-TE scenario, as here the primary reserve is not counted, and in the other cases there is no economic advantage of investing in more capacity than is actually used).

As evident in Figure 7, the year, the policy scenario, and the network tariffs all have significant impacts on the installed capacity and marketed flexibility. Focussing on the scenarios without reserves first (first row), the different years would result in significantly different levels of capacity extension, due to the higher absolute price spreads (cf. Figure 4) and resulting higher provision of flexibility on the day-ahead market. As the process has a minimum running capacity, the provided average weekly day-ahead flexibility is lower than the installed capacity, as the capacity below $\underline{K}$ cannot be utilised. With increasing network tariffs, the optimum installed capacity is reduced, as it represents an additional fixed cost per MW. This is analogous to the investment-reducing effect that capacity based network tariffs have on generation investment, which is also found in equilibrium models (Grimm et al., 2016).

If the provision of primary reserve is included (row 2), this increases the absolute installed capacity, as the operator of the process can market its flexibility on the (for this process, in most weeks) more lucrative primary reserve market, but also profit from weeks with relatively higher day-ahead market prices and market more flexibility on the day-ahead market. Assuming that any participant in the reserve, could instead reduce their day-ahead (or intraday) electricity market cost instead, it follows that marginal bidder on the reserve market is just indifferent to the opportunity cost of foregoing greater participation in the wholesale market (i.e. the two 
markets are in equilibrium). However, this is not necessarily true for non-marginal bidders, so the preference for reserve markets of the discussed production process is not in contradiction to theory. Nonetheless, in some weeks, a mix of day-ahead flexibility and primary reserve is chosen (cf. Figure A-7 in Appendix), which is not at the upper primary reserve constraint, indicating the indifference of the operator between the two markets and its (hypothetical role) as marginal bidder. With increasing network tariffs, overall capacity is reduced, and provision of primary reserves declines more strongly than day-ahead flexibility. The reason is that at lower excess capacities, the marginal value of providing day-ahead flexibility can be higher, as only the few most expensive hours are avoided. The larger the excess capacity, the less is the marginal value of providing additional day-ahead flexibility, as less expensive hours of the price duration curve are avoided. The network tariff exception for the primary reserve is such a strong implicit subsidy for the market that the primary reserve is always provided up to the technical limit of the process. This also leads to more absolute installed capacity, but less provided absolute day-ahead flexibility than in the case without the tariff exception.

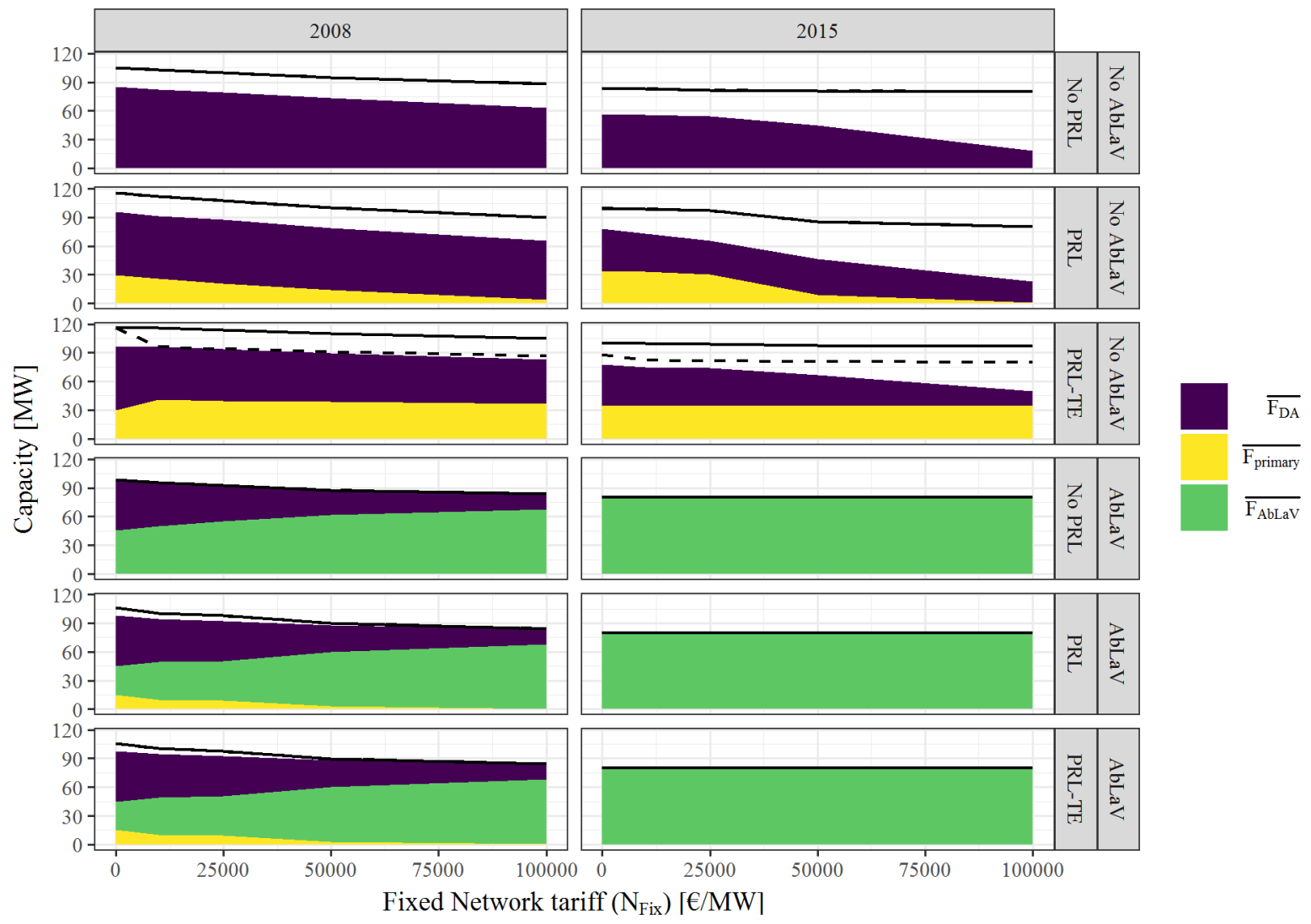

Figure 7 Endogenous capacity investments in different policy and network scenarios

The effect of the emergency demand reserve (AbLaV) differs between the years. Due to the low prices and volatility in 2015, the introduction of $\mathrm{AbLaV}$ leads to no investment in additional capacity and the process is run flat at $80 \mathrm{MW}$, providing only emergency AbLaV reserve. ${ }^{3}$ For 2008, there is a mix between all three reserves, with a larger share for the $\mathrm{AbLaV}$ reserve as the fixed network tariff increases. As higher (fixed) network tariffs reduce the optimal installed capacity, this favours the use of AbLaV (cf. Section 4.3.2).

\footnotetext{
${ }^{3}$ This ignores that the reserve may be triggered; however, this has rarely happened in practice and it is possible to buy the EDC product in bulk.
} 


\section{Conclusions}

A chlor-alkali process with an intermediary storable good is modelled with deterministic cost minimization on the day-ahead market, co-optimised with revenues from two different power market reserves, the primary reserve and the reserve for interruptible loads (AbLaV). Endogenous investment decisions in excess capacity of the electrolysis process, as well as storage, are also modelled. Different regulatory designs for the reserves, as well as the impact of network tariffs are investigated using the developed model and flexibility metrics developed to compare flexibility provision in different markets.

Several conclusions can be drawn from this study. Generally, for flexibility potentials from industrial demand response to be available, excess capacities in the process are needed in order to shift load (if only deferrable load shifting is assumed) and subsequently make up for lost production. The smaller the excess capacity, the higher is the asymmetry between high potential (short) load reduction and (long) small load increases. There are diminishing cost savings for larger excess capacities, as the most expensive electricity hours are avoided first.

Fixed peak-demand (capacity-based) network tariffs (demand charges) can be detrimental for the provision of industrial demand response; however, this is more relevant if new investments in excess capacity are necessary to realize demand response potentials, as the fixed network tariffs practically increase investment costs and can reach the same order of magnitude as the investment itself. For already existing excess capacities, unreduced network tariffs at the high end of currently existing network tariffs (or very low earning opportunities due to low electricity price spreads) may inhibit the provision of demand response from higher excess capacities on the day-ahead market, by limiting the optimal peak load over the year below its physical limit. This confirms the hypothesis that these peak demand charges may create significant economic distortions, making the trade-off how to allocate the network fixed costs yet more complicated.

For existing excess capacities we find that the day-ahead market and reserve markets are substitutes for each other, as the available flexibility can only be sold once. Whereas an increased excess capacity of the process leads to higher flexibility provision (and additional revenues) on the day-ahead market and the primary reserve markets, the reverse is true for the interruptible load ordinance $(\mathrm{AbLaV})$. This is the case as it encourages a flat load profile (due to its requirement to be entirely shut down), and is thus less attractive as compared to the other markets as revenues do not increase with increased excess capacities.

For endogenous investment decisions, day-ahead flexibility provision and primary reserve markets continue to split the availability flexibility between them, however, they are complementary in the sense that combined they lead to higher increase in excess capacity and absolute provided flexibility. On the other hand, the interruptible load reserve is mostly exclusively marketed (except at very low peak-demand network tariffs) and keeps investment in additional capacity low.

Peak-demand network tariffs, introduce a bias to market flexibility in the interruptible load reserve. An exception from peak demand network tariffs for the primary reserve leads to increased provision of primary reserve instead of on the day-ahead market and may increase investments in flexibility capacity, thus countering the negative impact of network tariffs. However, from the system perspective, this may be inefficient as it introduces a nonfundamentally founded bias between different markets. A topic for future research are systemwide evaluations of such effects and the distribution of the time scales of flexibility provided, especially under higher shares of renewable energy sources. 


\section{Acknowledgements}

The authors are grateful for financial support from the German Federal Ministry of Education and Research under grant number 03SFK3S0 (Synergie project). The views and opinions expressed in this publication do not necessarily reflect the views of the Ministry. We would like to thank Jan Stede, Karsten Neuhoff and Christian Calvillo for critical feedback.

\section{Literature}

Ambrosius, M., Grimm, V., Sölch, C., \& Zöttl, G. (2018). Investment incentives for flexible demand options under different market designs. Energy Policy, 118, 372-389.

Ausfelder, F., Dura, H. E., Arnold, K., Holtz, G., Dietrich, R.-U., \& Estelmann, S. (2018). Flexibilitätspotenziale und -perspektiven der Chlor-Alkali Elektrolyse. In F. Ausfelder, A. Seitz, \& S. Von Roon (Eds.), Flexibilitätsoptionen in der Grundstoffindustrie : Methodik, Potenziale, Hemmnisse (pp. 24 - 30). Frankfurt am Main: DECHEMA.

Bohlayer, M., Fleschutz, M., Braun, M., \& Zöttl, G. (2020). Energy-intense productioninventory planning with participation in sequential energy markets. Applied Energy, $258,113954$.

Eid, C., Koliou, E., Valles, M., Reneses, J., \& Hakvoort, R. (2016). Time-based pricing and electricity demand response: Existing barriers and next steps. Utilities Policy, 40, 1525.

EWI. (2019). Preiszeitreihe 2030 Szenario KS95.

Gils, H. C. (2014). Assessment of the theoretical demand response potential in Europe. Energy, 67, 1-18.

Grimm, V., Martin, A., Schmidt, M., Weibelzahl, M., \& Zöttl, G. (2016). Transmission and generation investment in electricity markets: The effects of market splitting and network fee regimes. European Journal of Operational Research, 254(2), 493-509.

Gruber, A.-M. (2017). Zeitlich und regional aufgelostes industrielles Lastflexibilisierungspotenzial als Beitrag zur Integration Erneuerbarer Energien. Technische Universität München.

Klobasa, M. (2007). Dynamische Simulation eines Lastmanagements und Integration von Windenergie in ein Elektrizitatsnetz auf Landesebene unter regelungstechnischen und Kostengesichtspunkten. ETH Zurich.

Knaut, A., Tode, C., Lindenberger, D., Malischek, R., Paulus, S., \& Wagner, J. (2016). The reference forecast of the German energy transition-An outlook on electricity markets. Energy Policy, 92, 477-491.

Langrock, T., Achner, S., Jungbluth, C., Marambio, C., Michels, A., Weinhard, P., ... Otto, A. (2015). Potentiale regelbarer Lasten in einem Energieversorgungssystem mit wachsendem Anteil erneuerbarer Energien. Climate Change 19, Umwelt Bundesamt.

Open Power System Data. (2019). Data Package Time series. Retrieved from: https://doi.org/10.25832/time series/2019-06-05

Otashu, J. I., \& Baldea, M. (2019). Demand response-oriented dynamic modeling and operational optimization of membrane-based chlor-alkali plants. Computers $\mid \&$ Chemical Engineering, 121, 396-408.

Paulus, M., \& Borggrefe, F. (2011). The potential of demand-side management in energyintensive industries for electricity markets in Germany. Applied Energy, 88(2), 432441.

Pérez-Arriaga, I. J., Jenkins, J. D., \& Batlle, C. (2017). A regulatory framework for an evolving electricity sector: Highlights of the MIT utility of the future study. Economics of Energy \& Environmental Policy, 6(1), 71-92.

Ramin, D., Spinelli, S., \& Brusaferri, A. (2018). Demand-side management via optimal 
production scheduling in power-intensive industries: The case of metal casting process. Applied Energy, 225, 622-636.

Regelleistung.net. (2019). Ausschreibungsübersicht. Retrieved from https://www.regelleistung.net/ext/tender/

Söder, L., Lund, P. D., Koduvere, H., Bolkesjø, T. F., Rossebø, G. H., Rosenlund-Soysal, E., . . Blumberga, D. (2018). A review of demand side flexibility potential in Northern Europe. Renewable and Sustainable Energy Reviews, 91, 654-664.

Summerbell, D. L., Khripko, D., Barlow, C., \& Hesselbach, J. (2017). Cost and carbon reductions from industrial demand-side management: Study of potential savings at a cement plant. Applied Energy, 197, 100-113.

Vallés, M., Reneses, J., Cossent, R., \& Frías, P. (2016). Regulatory and market barriers to the realization of demand response in electricity distribution networks: A European perspective. Electric Power Systems Research, 140, 689-698.

Yates, J. K. (2016). Engineering Economics: CRC Press. 


\section{Appendix A.}

\section{A.1 System information}

The model was run on the following machine, using GAMS with CPLEX as a solver.

Processor: Intel® Core ${ }^{\mathrm{TM}}$ i7-6700 CPU @ $3.40 \mathrm{GHz}$

Ram: 16 GB

System type: 64 bit

GAMS version:

GAMSIDE build $\quad 66510 / 66732$

GAMS Release 25.1.1 r66732 WEX-WEI x86 64bit/MS Windows

Release Date Released May 19, 2018

\section{A.2 Data preparation}

The electricity price data was prepared in the following way.

Table A-1 Data preparation for the studied years

\begin{tabular}{|l|l|}
\hline Year & Description \\
\hline 2008 & $\begin{array}{l}\text { The last two days of the year 2008 including } 30 \text { and } 31 \text { of December (Tuesday and } \\
\text { Monday) are omitted so the year ends on Sunday } 28 \text { December. Because the first } \\
\text { day of the year is Tuesday, add the last day of the year } 2007 \text { is added to the data of } \\
\text { this year. }\end{array}$ \\
\hline 2015 & $\begin{array}{l}\text { The year 2015, begins and ends on Thursday. The last three days of } 2014 \text { are } \\
\text { added to the beginning of this year and the last } 4 \text { days of } 2015 \text { are omitted. }\end{array}$ \\
\hline $\begin{array}{l}\text { The year } 2030 \text { starts and ends on Tuesday. The last two days of the year should be } \\
\text { omitted and the last day of the year 2029 should be added to the data of this year. } \\
\text { Since we do not have the Electricity prices for year 2029, we delete the last day of } \\
\text { the year 2030 and the data of this year begins on Tuesday and ends on Monday. } \\
\text { We still have 52 weeks and 8736 hours of data for this year. }\end{array}$ \\
\hline
\end{tabular}




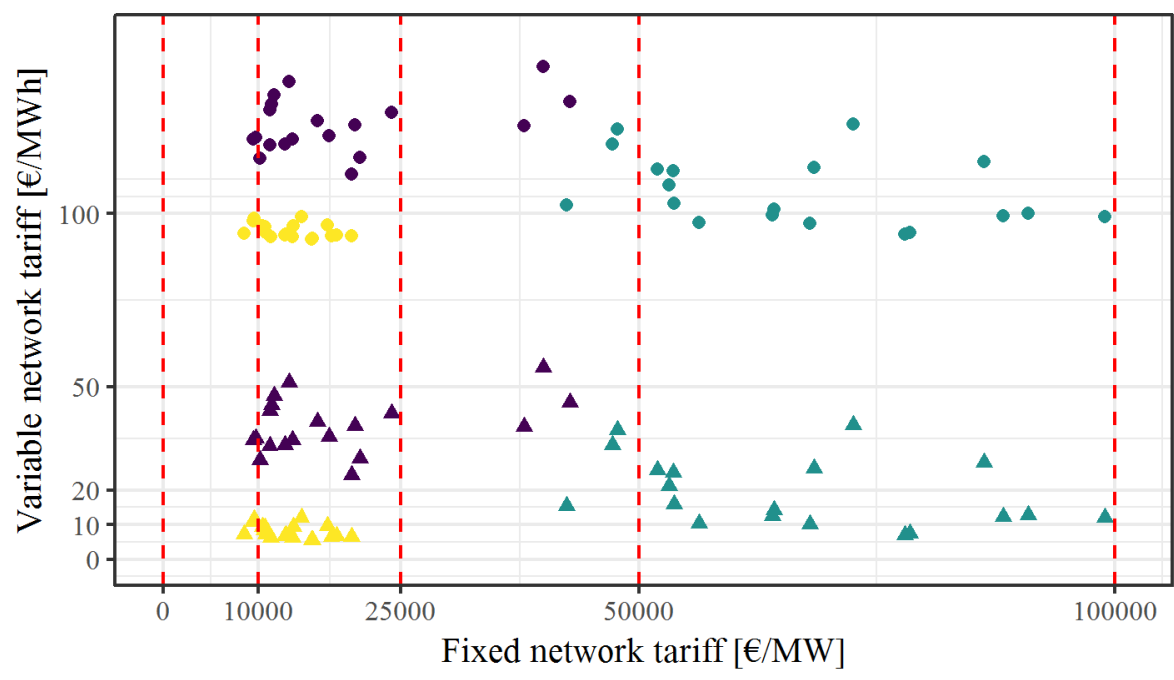

Full Load Hours [h]

- $<2500$

$>=2500$

$>=7000(80 \%$ rebate $)$

Levy reduction

- FALSE

- TRUE

Figure A-1 Fixed network tariff scenarios (in red) compared to network tariffs from Westnetz, Stuttgart Netze and EWE in 2018, grouped by full load hours (incl. 80\% reductionaccording to StromNEV \$19 (2), and a typical levy reduction following the Monitoringbericht 2018, BNetzA, p. 274 for 24GWh yearly consumption

\section{A.3 Additional tables and figures}

Table A-2 Relative day-ahead market cost reductions (no network tariff, no reserves)

\begin{tabular}{|l|l|l|l|l|l|l|l|l|l|}
\hline $\begin{array}{l}\text { Year/Capacity } \\
{[\mathrm{MW} / \%]}\end{array}$ & 80 & 81 & 85 & 90 & 95 & 100 & 110 & 120 & 140 \\
\hline 2008 & 100 & 98.12 & 94.14 & 91.12 & 88.68 & 86.57 & 83.11 & 80.38 & 76.43 \\
\hline 2015 & 100 & 98.71 & 95.28 & 92.14 & 89.6 & 87.46 & 84.03 & 81.44 & 77.68 \\
\hline 2030 & 100 & 97.78 & 92.57 & 87.97 & 84.29 & 81.16 & 76.02 & 71.83 & 65.18 \\
\hline
\end{tabular}

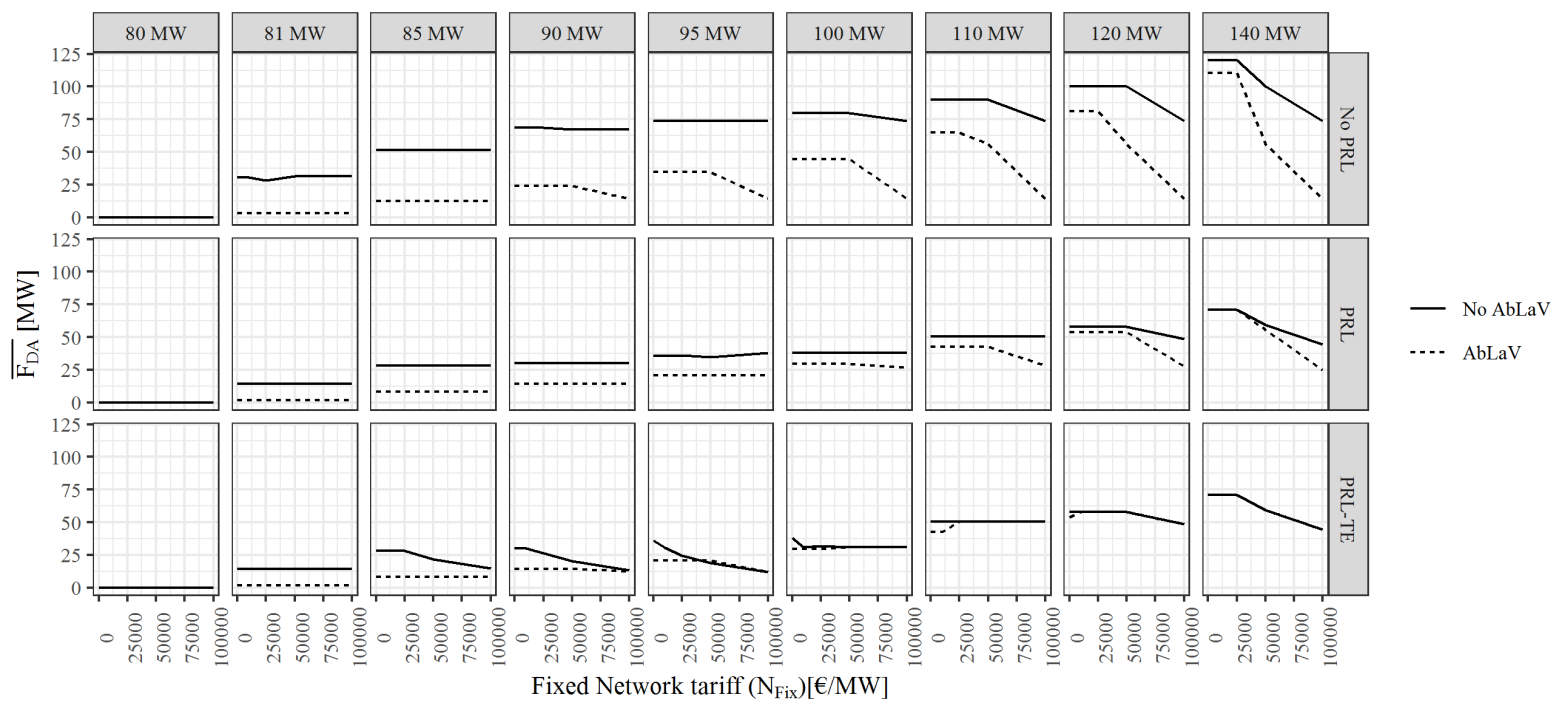

Figure A-2 Detailed assessment of regulatory impacts on $\overline{F_{D A}}$. 


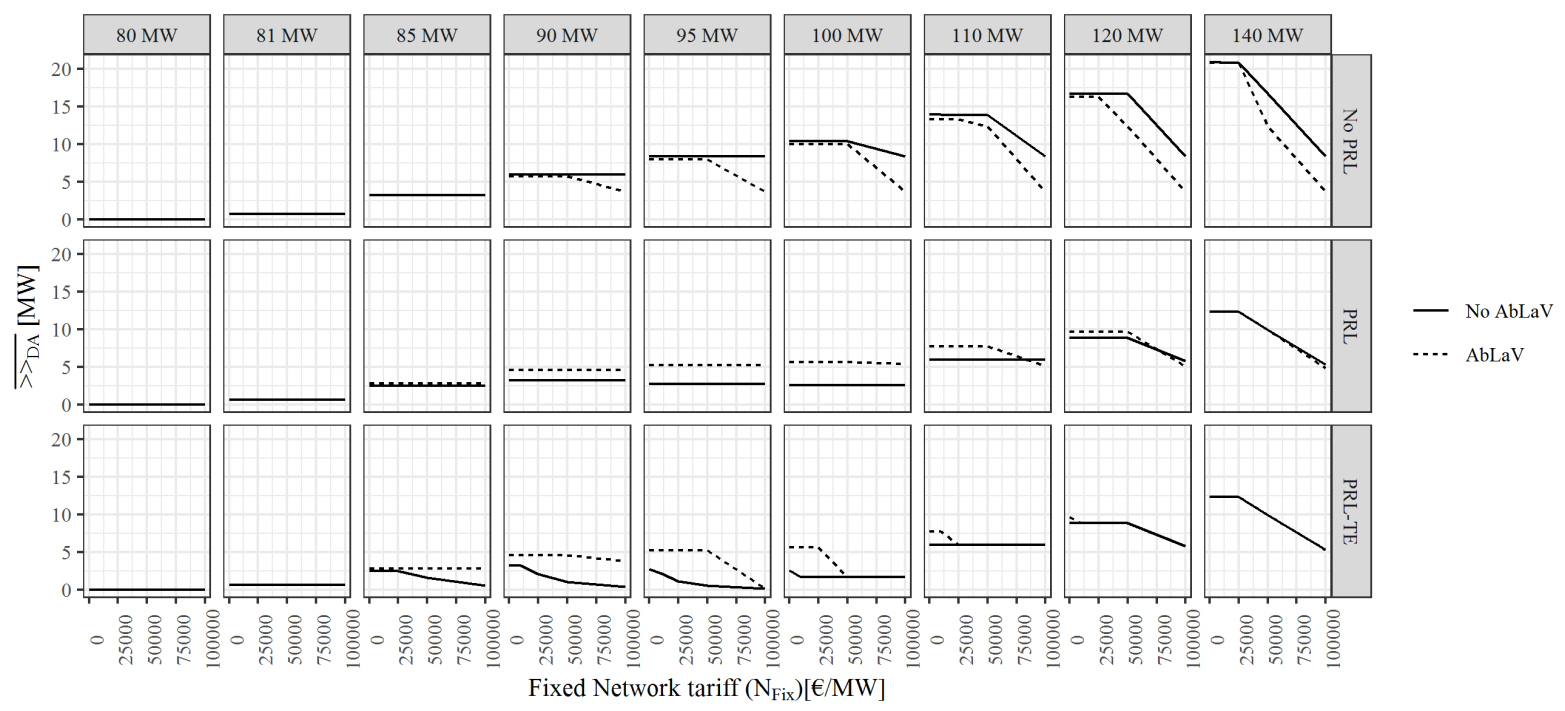

Figure A-3 Detailed assessment of regulatory impacts on shifted production $\left(\gg_{D A}\right)$.

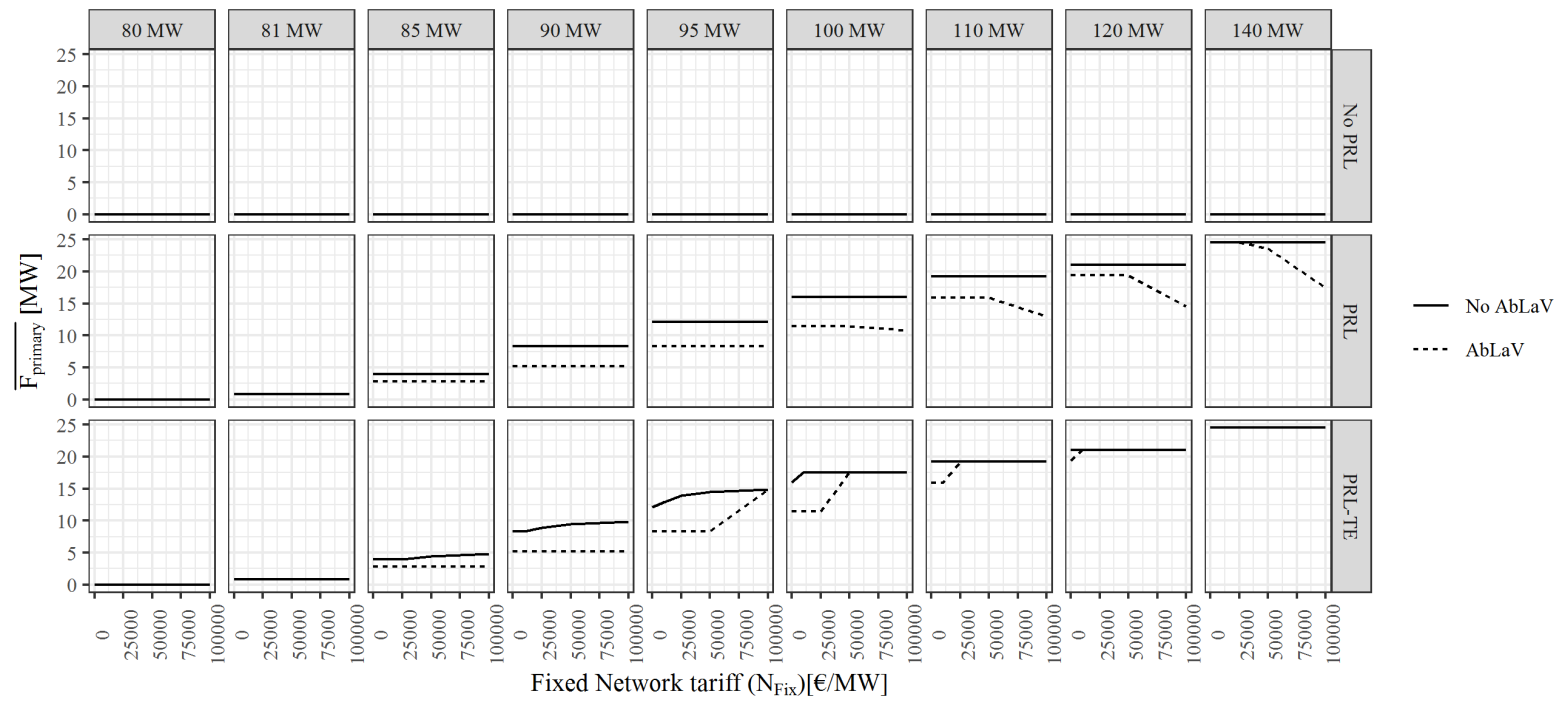

Figure A-4 Detailed assessment of regulatory impacts on $\overline{F_{\text {primary }}}$.

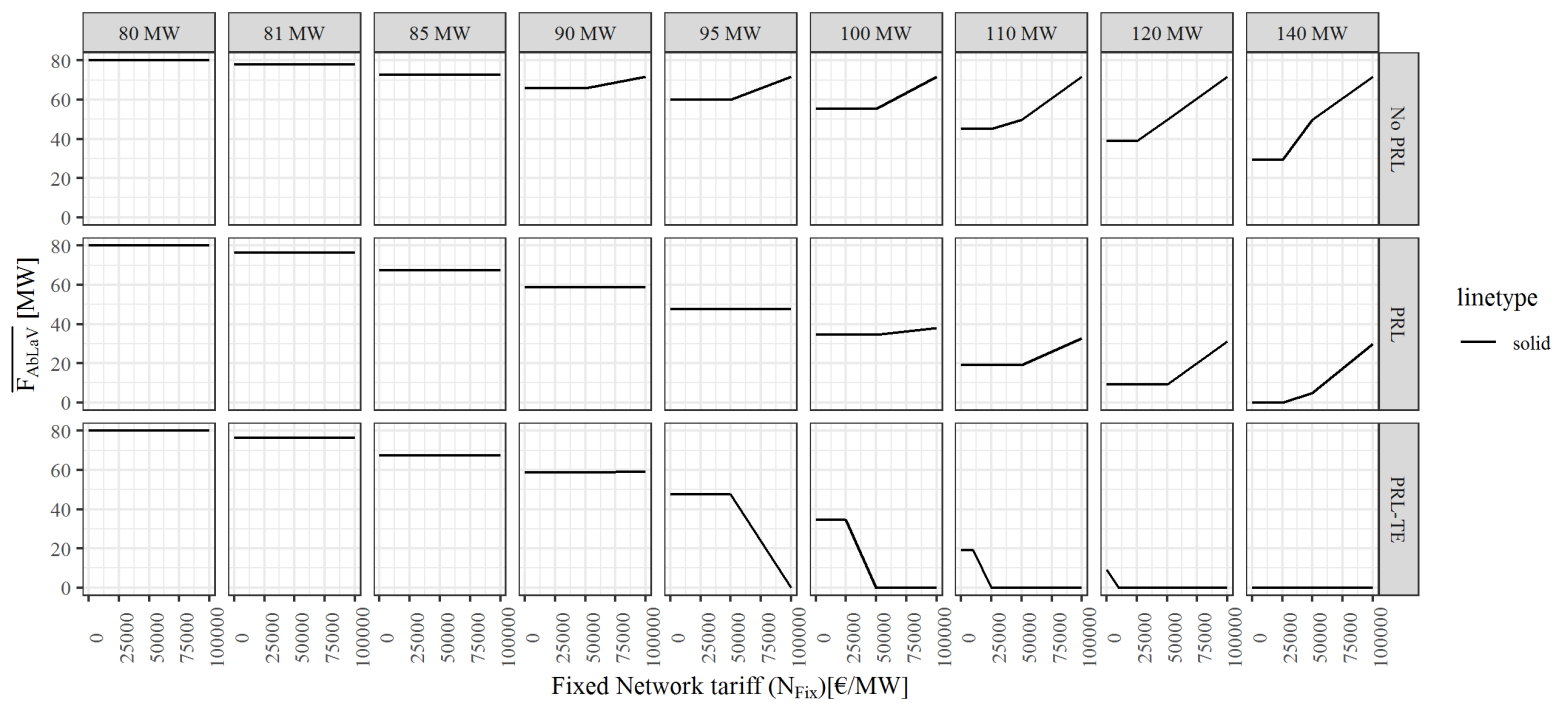


Figure A-5 Detailed assessment of regulatory impacts on $\overline{F_{\text {AbLaV }}}$.

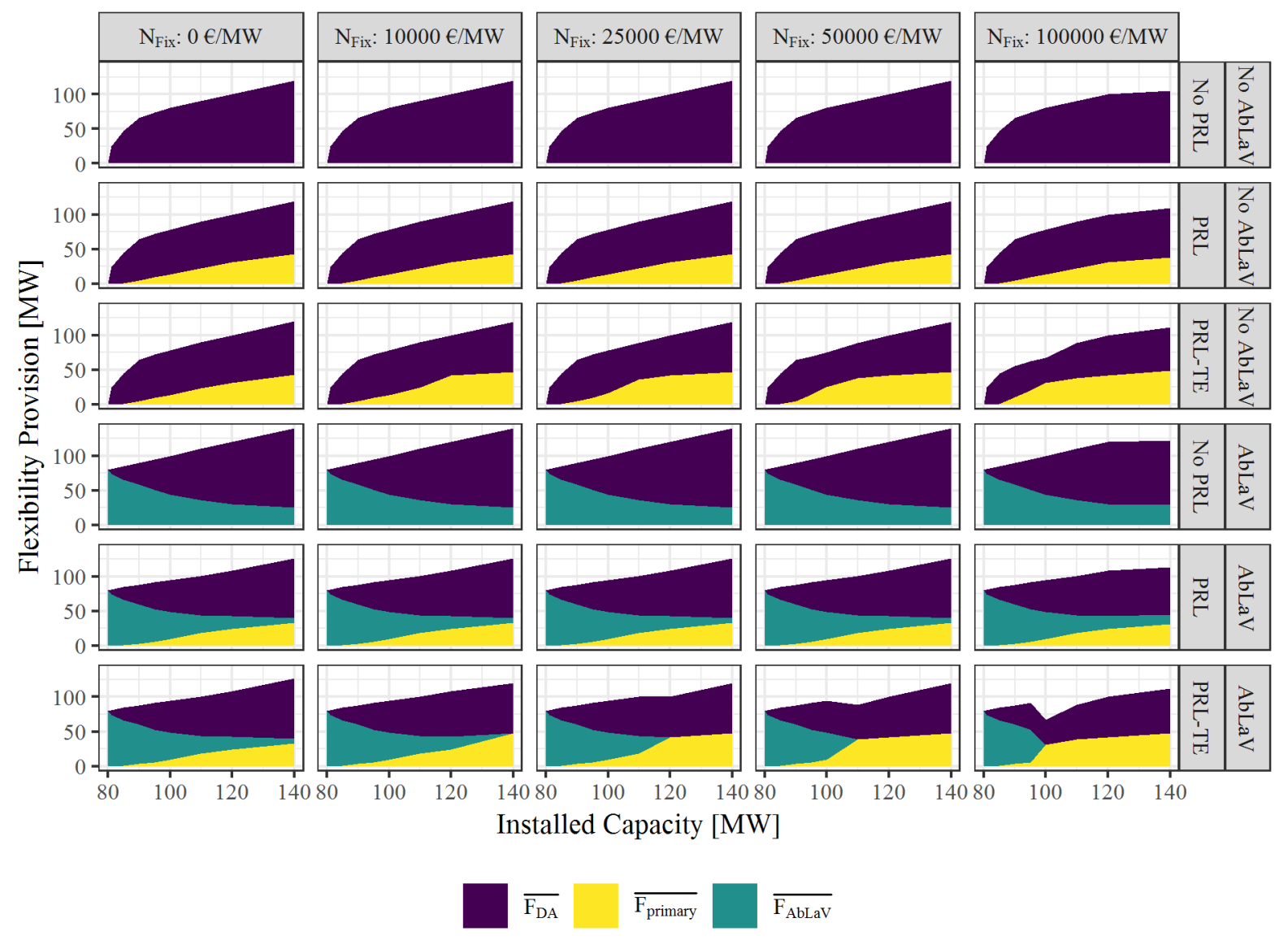

Figure A-6 Flexibility provision on flexibility markets in the year 2015 


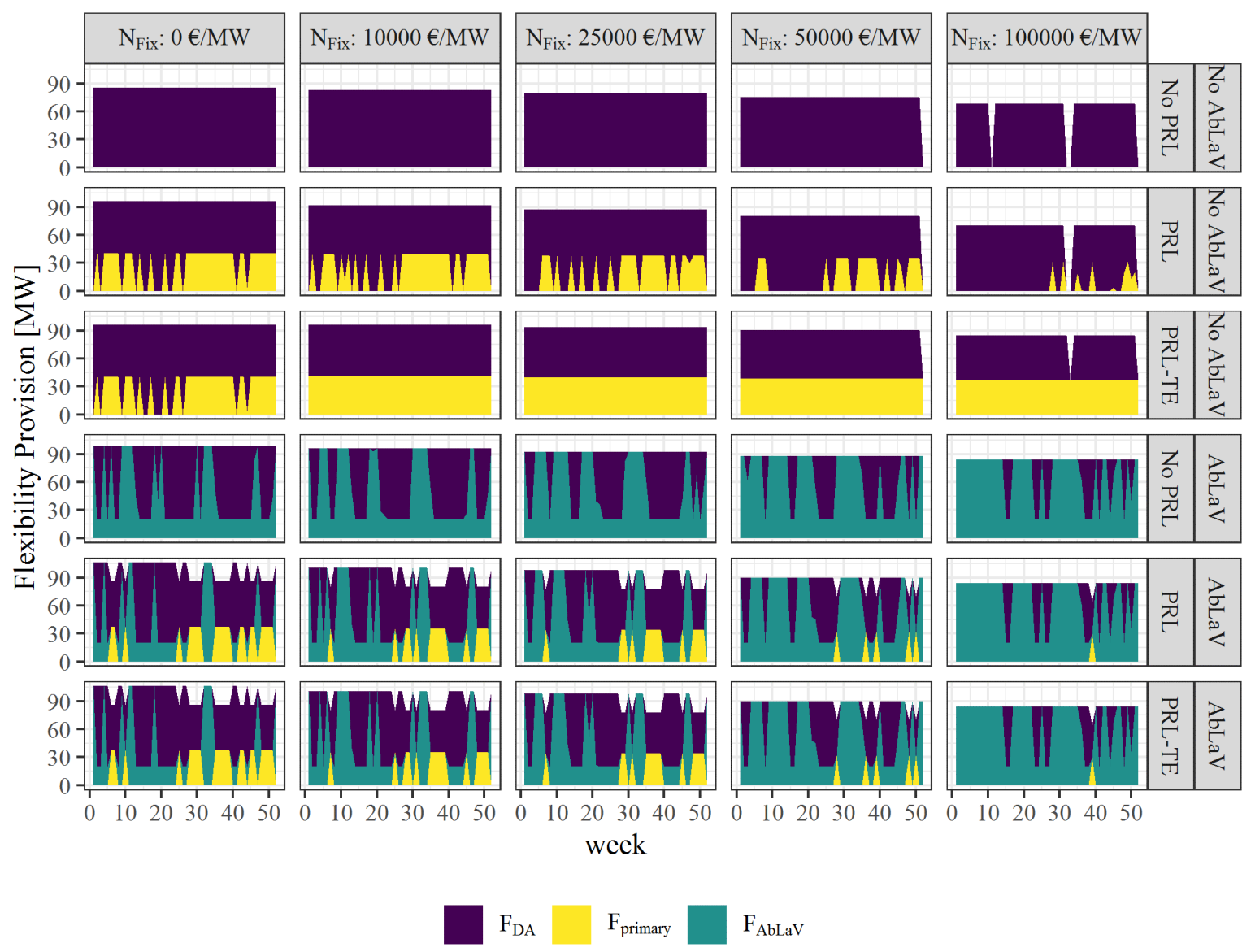

Figure A-7 Weekly reserve provision under endogenous investment in 2008 